\title{
FORMAÇÃO CONTINUADA DE PROFESSORES ALFABETIZADORES: REFLEXÕES TEÓRICAS E PRÁTICAS 1
}

\section{CONTINUING EDUCATION OF LITERACY TEACHERS: THEORETICAL AND PRACTICAL REFLECTIONS}

\author{
Simone Weide Luiz ${ }^{2}$ \\ Universidade do Vale do Rio dos Sinos \\ Cátia de Azevedo Fronza ${ }^{3}$ \\ Universidade do Vale do Rio dos Sinos \\ Isaías dos Santos Ildebrand ${ }^{4}$ \\ Universidade do Vale do Rio dos Sinos
}

\begin{abstract}
Resumo: No Brasil, a aquisição da leitura e da escrita não ocorre da forma esperada pela escola e pela sociedade. Devido a isso, professores precisam lidar de forma qualificada com essa demanda. Com foco nesse cenário, discutem-se implicações e modos de pensar na/a formação continuada, a fim baixar os índices de analfabestimo funcional, com a perspectiva de que isso se dará quando as práticas de letramento forem promovidas na escola. Apresentam-se, neste artigo, três estudos sobre formação continuada realizados com professores de anos iniciais, dialogando com pesquisa de Doutorado da primeira autora, voltada a essa temática. Ressalta-se a premência de práticas de formação como as evidenciadas neste artigo, porque avigoram o trabalho com a alfabetização e fortalecem o letramento desde o início da escolarização.

Palavras-Chave: Formação Continuada; Alfabetização; Letramento.

1 O presente trabalho foi realizado com apoio da Coordenação de Aperfeiçoamento de Pessoal de Nível Superior - Brasil (CAPES) - Código de Financiamento 001.

2 Endereço eletrônico: simonewluiz@hotmail.com.

3 Endereço eletrônico: catiaaf@unisinos.br.

4 Endereço eletrônico: isaias.brand@hotmail.com.
\end{abstract}


Abstract: In Brazil, the acquisition of reading and writing does not occur as expected by the school and society. Because of this, teachers need to deal with this demand in a qualified way. Focusing on this scenario, implications and ways of thinking about continuing education are discussed, in order to lower functional illiteracy rates, with the perspective that this will happen when literacy practices are promoted at school. This article presents three studies on continued education carried out with teachers of initial years, dialoguing with doctoral research of the first author, focused on this theme. It is important to emphasize the urgency of formation practices like the ones highlighted in this article, because they advance the work with literacy and strengthen literacy from the beginning of schooling.

Keywords: Continuing Education; Initial Reading Instruction; Literacy.

\section{INTRODUÇÃO}

A aquisição da leitura e da escrita no Brasil, considerada, de modo geral, aquém do esperado, está além da aprendizagem dos alunos em si. Também são necessários professores capacitados e motivados, uma estrutura escolar adequada, alunos com condições socioeconômicas dignas, entre vários outros fatores.

Sabemos que os estudantes precisam receber todas as condições possíveis para que aprendam da melhor forma e dentro do tempo esperado, em um sistema de ensino dividido em etapas (anos) para as quais há um nível de conhecimento a ser atingido. Há, contudo, outra personagem nesse processo de ensino-aprendizagem que também é indispensável: o professor.

A temática deste artigo surgiu de uma pesquisa de Doutorado em andamento desde 2018. A pesquisa é uma parceria com o departamento pedagógico da secretaria de educação de um município do interior do Rio Grande do Sul. As então coordenadoras pedagógicas do município sugeriram um trabalho em conjunto entre a pesquisadora e os professores alfabetizadores, para verificar o atual cenário da alfabetização do município. Segundo as coordenadoras, ainda havia muitos casos de alunos que chegavam ao $4^{\circ}$ ano do Ensino Fundamental sem estarem alfabetizados. Além disso, destacaram-se 
queixas tanto por parte da coordenação, quanto por parte de professores, de que não há um engajamento entre o trabalho dos docentes da rede, ou seja, cada professor trabalha à sua maneira, a partir das diretrizes do município.

Essa situação não é exclusividade do município, pois vê-se em todos os lugares, inclusive na mídia, que as escolas estão passando por uma crise de leitura, que tem como consequência o chamado "analfabetismo funcional", fenômeno que revela a "incapacidade dos indivíduos de fazer uso efetivo da leitura e da escrita nas diferentes esferas da vida social" (NUNES, 2018, p. 82). Com frequência, a responsabilidade por essa condição é dada aos professores, cuja formação não é considerada suficiente para a realização de seu trabalho.

Muito se diz sobre o "analfabetismo funcional", que aumentou de 2015 a 2018. Isso vai ao encontro do fato de que um problema importante de pesquisa em nosso país é a inserção dos indivíduos em práticas de letramento (KLEIMAN et al., 2019). Entende-se como um sujeito do letramento aquele que lê e escreve, utilizando essas habilidades de forma efetiva, interagindo socialmente, culturalmente, politicamente, economicamente e cognitivamente (DORNELLES, 2019).

Tem-se, portanto, como temática importante deste artigo o ato de ler, já que a leitura não é apenas a decodificação de letras e palavras, convertendo-as em som. Ler significa atribuir significados, sendo prática social essencial para entender o mundo. O professor, então, precisa delimitar estratégias para que os seus alunos leiam e compreendam os gêneros que constituem sua realidade social, envolvendo-os nas práticas sociais para compreenderem e agirem em seu meio.

Questiona-se, entretanto, o que pode ser feito para que os professores tenham condições de auxiliar na superação da crise de leitura enfrentada pela população brasileira. Esse questionamento ganha ênfase em estudos como o de Oliveira et al. (2015), quando se referem à má formação de professores como um 
dos fatores responsáveis pela atual crise na leitura, além da preferência do uso da tecnologia pelos jovens e das práticas de leitura desmotivadas pela escola. Diante desse cenário, este artigo aborda possibilidades de contribuir para esta frente, dando foco a estudos sobre situações de formação continuada, considerados também relevantes para quem trabalha com o ensino da leitura e da escrita.

A formação continuada de professores tem sido entendida como um processo permanente de aperfeiçoamento dos saberes necessários à atividade profissional, realizado após a formação inicial, com o objetivo de assegurar um ensino de melhor qualidade aos educandos. (CHIMENTÃO, 2009, p. 3)

Magalhães e Azevedo (2015) defendem que a formação continuada é inerente a todos os profissionais, independentemente de sua área de atuação. As autoras acreditam que acompanhar pesquisas, produções teóricas, fazer cursos e inovar em suas práticas são procedimentos que conduzem a formação inicial.

Sob essa perspectiva, o primeiro estudo selecionado para orientar este artigo é um trabalho desenvolvido com dois grupos de professores de anos iniciais, que participaram do programa de formação continuada Pró-Letramento, Alfabetização e Linguagem, oferecido pelo então Ministério de Educação e Cultura (MEC), coordenado pela Universidade Federal de Pernambuco (UFPE), em parceria com um município da serra gaúcha, de setembro de 2008 a julho de 2009. O foco central desse trabalho foi buscar formas de melhorar os índices de aprendizagem de alunos do Ensino Fundamental, considerando que o professor é o sujeito que atua de forma direta no processo de ensino-aprendizagem (EITELVEN; FRONZA, 2012). Sabe-se que o programa Pró-Letramento, Alfabetização e Linguagem foi e ainda é alvo de críticas, porém acreditamos que esse exemplo específico pode contribuir com a proposta deste artigo. 
Seguindo uma ordem cronológica, é apresentado o projeto Alfaletrar, proposto por Sousa (2016), em sua dissertação de Mestrado, desenvolvido no município de Lagoa Santa/MG, na região metropolitana de Belo Horizonte. O projeto é uma ação de formação que vem sendo desenvolvida há oito anos, tendo como alvo os professores da rede municipal, cujas temáticas são a alfabetização e o letramento.

O trabalho mais atual, que também tem como alvo a formação continuada de professores, foi desenvolvido por Nunes (2018), em uma escola pública da periferia da cidade de Belém/PA. Foi realizada uma prática de formação contínua com professores alfabetizadores, centrada na escola, com cerne na mudança de concepções e práticas alfabetizadoras. Destaca-se a atuação de professores como criadores, planejadores e gestores de projetos, tanto formativos, quanto de pesquisa, para aprimorar suas práticas.

A partir desses exemplos, discutem-se, neste artigo, formas de pensar a formação continuada para professores alfabetizadores de modo a auxiliá-los na difícil missão de melhorar os índices de alfabetização, com uma perspectiva de que isso se dará quando o letramento entrar de vez na sala de aula. Buscamos um estudo de análise das três pesquisas supracitadas (EITELVEN; FRONZA, 2012; SOUSA, 2016; NUNES, 2018), verificando em que aspectos elas se complementam e/ou se distinguem. É importante frisar que o objetivo final dessas pesquisas é que os professores possam realizar um trabalho coletivo para que os alunos atinjam um dos propósitos mais importantes da fase em que se encontram: realizar uma leitura sendo capazes de construir significado, conforme Kato et al. (1998), Matencio (2000), Ferreira e Dias (2002) etc.

$\mathrm{O}$ artigo está organizado em quatro partes. Inicialmente, reflete sobre alfabetização, letramento e sua importância para o desenvolvimento da leitura e da escrita. Na sequência, há o detalhamento da pesquisa que motivou este artigo, seguida pela apresentação dos três estudos motivadores da pesquisa. Depois 
disso, procede-se à análise das percepções e reflexões acerca dos referidos estudos, encerrando o texto por meio das considerações finais.

\section{OS DESAFIOS DA ALFABETIZAÇÃO E DO LETRAMENTO PARA O PROFESSOR}

Alfabetizar não é tarefa fácil, ainda mais em um contexto em que tanto se discute o uso ou não de uma ou mais metodologias. Ferreiro (2001) afirma que a criança não deve ser vista como uma tábua rasa, que nela podem ser inscritas letras ou palavras conforme determinado método. A autora ainda reforça que o que é "fácil" ou "difícil" não se define pela perspectiva do adulto. Para ela, os métodos são sugestões, incitações, práticas rituais ou conjunto de proibições.

Conforme Soares (2003), durante décadas, houve a busca por um método de ensino, como o silábico, o global, o fônico ou um método misto. Como destaca a autora, o processo de aquisição da escrita sob uma concepção associacionista consideraria o método como determinante para a aprendizagem, pois seria através da "exercitação de habilidades hierarquicamente ordenadas que a criança aprenderia a ler e a escrever" (SOARES, 2003, p. 89).

Soares (2018, p. 50) afirma ainda que "métodos são uma questão, não são $a$ questão". Segundo a autora, "é ilusório supor que métodos atuem independentemente da interferência" (SOARES, 2018, p. 50) de fatores sociais, culturais, econômicos e políticos. Também deve ser observado que tanto os alfabetizadores quanto os alfabetizandos se distinguem por características pessoais, lembrando que estes possuem experiências de aprendizagem anteriores à alfabetização.

Diante disso, entende-se que os fatores que podem se interpor aos métodos de alfabetização são numerosos e complexos. Ademais, quem ensina a ler e a escrever não são os métodos, mas o alfabetizador. O professor é quem ele 
é, faz uso específico dos métodos e acrescenta muito a eles, considerando quem é o alfabetizando, o contexto onde ocorre e as condições (SOARES, 2018).

Nota-se que a alfabetização vem tomando diferentes proporções, mais complexas, que envolvem aspectos do sujeito leitor que vão além do decodificar. Deve-se pensar de forma muito mais ampla, observando o indivíduo não por si só, mas dentro de uma rede de comunicação. Isso significa que, quando uma criança entra na escola, ela já passou por inúmeras experiências, já interagiu com seus pais, familiares e colegas da educação infantil, já conheceu diferentes lugares e já entrou em contato com uma gama de gêneros textuais/discursivos.

Essa visão mais ampla da alfabetização exigiu que aparecessem outras práticas de ensino da língua na escola. Surgiu então o termo "letramento", supracitado, que é associado à alfabetização, mas não é somente a aprendizagem do sistema alfabético e de suas convenções, mas é uma "introdução da criança às práticas sociais da língua escrita" (SOARES, 2018, p. 27).

Busca-se o que se chama "alfabetizar letrando", quando há uma intricada interação entre práticas sociais da língua escrita e o sujeito que lê ou escreve, exigindo determinadas habilidades e exercitando, simultaneamente, diferentes competências (SOARES, 2018). Isso significa, conforme Moreira e Rocha (2013), que codificar e decodificar não são suficientes para realmente experimentar a cultura escrita, respondendo às necessidades do meio social. O indivíduo deve letrar-se, dominando tanto a arte de ler e escrever como a capacidade de lidar de forma autônoma com o uso cotidiano de leitura e escrita em diferentes contextos.

Rojo e Barbosa (2009) trazem outro conceito, que corrobora tanto com a alfabetização quanto com o letramento, que é o alfabetismo. Segundo as autoras, ler envolve as capacidades letradas de decodificar, compreender inferências, interpretar, estabelecer relações, situar o texto em seu contexto etc. $\mathrm{O}$ ato de escrever, por sua vez, envolve as capacidades de codificar, normatizar 
(ortografia, notações), comunicar, textualizar, situar o texto em seu contexto, intertextualizar etc.

É importante considerar também que a alfabetização e o letramento podem andar juntos. Segundo Kleiman (2005), o letramento inclui a alfabetização, necessária para que um indivíduo seja considerado letrado, mas não o suficiente para que isso ocorra. Podemos pensar que a alfabetização é uma prática de letramento, parte das "práticas sociais de uso da escrita na instituição escolar" (KLEIMAN, 2005, p. 12).

Refletindo sobre essas temáticas, questiona-se sobre o que o professor precisa fazer para que o aluno leia, escreva, compreenda os textos lidos, comparando-os com outros textos etc. Essa tarefa múltipla exige muita preparação e estudo. Não basta que o docente seja formado, e bem formado, uma vez que ele precisa estar ciente do que acontece no mundo e, principalmente, da realidade de seus alunos. Em tal contexto, a formação constante e a troca de conhecimentos/experiências com os pares e com os alunos podem ser alternativas capazes de fortalecer as linguagens envolvidas nesse processo.

Os professores possuem a enorme responsabilidade de materializar as políticas educativas. Por isso, criam-se nas instituições formadoras expectativas em relação à formação de professores. Essas instituições buscam, conhecem, interpretam e ressignificam as políticas, para agirem em favor de um ideal educativo. O professor é o agente da mudança da aprendizagem de seus alunos, mas, para isso, precisa de uma formação para lidar com a realidade do ambiente alfabetizador (NUNES, 2018).

Nunes (2018), a partir de discussões teóricas, aponta para a perspectiva de que a formação de professores, inicial ou contínua, deve ser constituída em um processo em que

a valorização das práticas educativas não se sobreponha às teorias que as fundamentam ou vice-versa, evitando-se, com isto, a clássica dicotomia entre 
teoria e prática tão presente ainda na formação de professores do Brasil em que, ora foca excessivamente nas metodologias e práticas de ensino, ora centraliza-se nos fundamentos teóricos das questões educativas. (NUNES, 2018, p. 20-21)

Outrossim, o professor deve ser sujeito ativo ao construir a sua formação e o desejo pelo aperfeiçoamento deve partir dele próprio. $\mathrm{Na}$ formação continuada, os professores não devem apenas executar um plano previamente dado a eles, ou prescrito, mas atribuir um sentido ao que estão fazendo, sendo capazes de auxiliar os alunos a fazerem o mesmo. Os professores devem ter orientações adequadas e acesso a diferentes gêneros e discursos, para analisar, comparar, perceber a estrutura e a linguagem das esferas onde os gêneros circulam (KERSCH, 2014).

Enfim, o professor tem uma difícil tarefa, que é trabalhar para unir teoria e prática. Não há uma solução prescrita para tudo o que acontece em sala de aula, mas há que se estudar o que acontece na rotina de um professor, para que todos, incluem-se aqui os acadêmicos e pesquisadores, possam ajudar nessa missão.

Em sua formação, o professor, além de estudar a teoria, deve perceber o que acontece com os demais, compartilhar as suas experiências, refletindo e buscando conhecer melhor a sua realidade social e a de seus alunos. Logo, analisar práticas de ensino-aprendizagem em contexto de alfabetização é um caminho efetivo para orientar o trabalho do professor. Prescrever, portanto, não cabe mais, porque cada realidade é repleta de subjetividades. Assim sendo, a formação de professores não é apenas defender uma ou outra perspectiva teórica, mas é adentrar-se no mundo do aluno. Isso, sabemos, não é tarefa fácil.

Na próxima seção, apresentamos a pesquisa que motivou a elaboração deste artigo. Além disso, será apresentada uma prática de formação de professores realizada no município. 


\section{CAMINHOS DA PESQUISA}

A pesquisa de tese que orienta este artigo está sendo desenvolvida em escolas de um município da serra gaúcha ${ }^{5}$. O município possui cinco escolas de Educação Infantil, 22 escolas de Ensino Fundamental e três estruturas de contraturno, onde os alunos ficam no turno inverso ao das suas aulas regulares. Ao todo, são quase oito mil alunos e 750 professores. A rede trabalha com crianças de quatro meses a adultos, na modalidade de Educação de Jovens e Adultos (EJA).

O tema desta pesquisa, classificada como pesquisa-ação ${ }^{6}$ e qualitativa ${ }^{7}$ foi proposto em reunião da pesquisadora com duas professoras do setor pedagógico da Secretaria de Educação (SEDUC) do município, em 2018. Então, a partir de real demanda da rede municipal, o foco da pesquisa volta-se à alfabetização dos alunos em fase de aquisição da leitura e da escrita. As servidoras do Departamento Pedagógico (DP) relataram que muitos alunos chegam ao final do $3^{0}$ ano do Ensino Fundamental sem estarem alfabetizados ${ }^{8}$.

O interesse por desenvolver a pesquisa aumentou ainda mais por ela ter sido iniciada a partir de uma necessidade das escolas do município de melhorar os índices de alfabetização de seus estudantes. Outro motivo foi o fato de o

\footnotetext{
5 O contato com os participantes iniciou apenas após a aprovação da pesquisa pelo Comitê de Ética em Pesquisa (CEP) da instituição de ensino superior, conforme CAEE $n$. 09230919.7.0000.5344.

6 De acordo com Heigham e Croker (2009), essa abordagem, como o próprio nome diz, envolve ação e pesquisa. A ação consiste em identificar e explorar um problema, uma pergunta, uma lacuna ou um quebra-cabeças dentro de seu contexto. No caso desta pesquisa, o contexto é a escola e, mais precisamente, a sala de aula. Essa ação, em geral, envolve mudanças ou intervenções em um local, com o intuito de melhorá-lo, modificá-lo ou desenvolvê-lo.

7 Na pesquisa qualitativa, os significados são socialmente construídos. Isso significa que o foco está nos participantes, em como eles experienciam um fenômeno em um contexto particular. São cenários naturais, como é a escola. O pesquisador vai até as pessoas, sempre reconhecendo a complexidade e a dinâmica dos ambientes (HEIGHAM; CROKER, 2009).

8 A partir da fala das professoras, os referidos alunos não conseguem realizar uma leitura significativa, eles apenas decodificam palavras, mas não são capazes de compreender ou falar sobre o que leram.
} 
assunto ser complexo e recorrente entre pesquisadores e professores e pela razão de o insucesso escolar existir de forma persistente, mesmo com as inovações pedagógicas e modificações no sistema de ensino das redes municipais. Trata-se de um compromisso político, com desafios para tentar captar a realidade dinâmica e complexa do contexto das escolas, assim como observa Cruz (2012).

O início da relação dessa pesquisa com o tema "formação de professores" ocorreu por meio de contato com 20 professores de turmas de $1^{\underline{o}}$ ano do Ensino Fundamental, cujos alunos têm, em média, 7 anos, da rede municipal na qual o estudo em foco vem sendo desenvolvido, em atividade de formação pedagógica realizada em março de 2019, ministrada pela pesquisadora, a convite da SEDUC. Nesse dia, houve uma discussão sobre a BNCC (Base Nacional Comum Curricular), tema sugerido pela SEDUC. Vários detalhes dessa formação estão publicados em Luiz et al. (2019), que relata o que aconteceu naquele momento, sob a perspectiva do trabalho realizado pelo professor.

No referido encontro de formação, desde os primeiros relatos, perceberam-se divergências entre opiniões dos docentes sobre a Base. Alguns deles, a favor do documento, pensavam mais no contexto do país como um todo, com suas diferenças em relação aos métodos e conteúdos trabalhados no $1^{\circ}$ ano. Segundo tais docentes, os alunos deveriam entrar no $1^{\underline{o}}$ ano com noções de leitura e escrita e sair alfabetizados. O professor é responsável por buscar alternativas para que isso aconteça, sendo capaz de adaptar os conteúdos propostos pela Base à realidade dos alunos (LUIZ et al., 2019).

Todavia, mesmo concordando que o aluno deve saber ler e escrever ao final do $1^{\mathrm{o}}$ ano, a maioria dos professores acreditava que havia lacunas a serem preenchidas antes da implementação da BNCC. Um exemplo é o fato de os livros didáticos ainda serem separados por disciplinas, não trabalhando as competências que os alunos devem adquirir ao longo de seu percurso escolar, 
como pensamento crítico, repertório cultural, responsabilidade, cidadania etc. (LUIZ et al., 2019).

Os professores relataram que não foram orientados sobre como trabalhar de forma interdisciplinar, pois, para desenvolver as competências esperadas, imagina-se que eles devam trabalhar em grupos, com docentes de diferentes disciplinas. No caso de um trabalho sobre repertório cultural, por exemplo, normalmente um professor de $1^{o}$ ano precisaria de parcerias com professores de história e artes (LUIZ et al., 2019).

Houve também uma discussão com os professores sobre as competências gerais da BNCC, pensando sempre em como trabalhá-las na rotina das aulas, unindo-as às disciplinas. Para uma melhor visualização prática sobre como fazer isso, os professores tiveram contato com o site "Nova Escola", onde há planos de aula gratuitos e alinhados à $\mathrm{BNCC}^{9}$, relacionados às competências estabelecidas no documento.

Ao final da atividade de formação, foi proposta uma tarefa para os professores, em duplas/trios. Nessa tarefa, cada grupo retirou, de duas caixinhas diferentes, um pedaço de papel com uma disciplina e outro com uma competência. Então, eles pensaram em uma atividade completa, unindo a disciplina e a competência selecionadas. Por exemplo, um grupo selecionou a tarefa de preparar uma atividade da disciplina de História que deveria ser relacionada à competência Repertório Cultural. Os professores prepararam planos de aulas em duplas/trios e apresentaram para os seus colegas ao final do evento.

Segundo os professores, a Base tem um texto bastante interessante e atrativo, mas necessita de mais orientações sobre como utilizá-la. Com isso, podese pensar que momentos de formação como esse devem fazer parte da rotina dos

\footnotetext{
9 Planos de aula alinhados à Base podem ser criados no endereço eletrônico $<$ https://novaescola.org.br/plano-de-aula/>.
} 
professores, pois é importante que haja oportunidades de trabalho e discussões em grupo, de trocas de experiências, por mais simples que pareçam ser.

Os momentos de formação tiveram continuidade em 2020, porém em formato não presencial e assíncrono, devido à suspensão das aulas em virtude da pandemia do Coronavírus (COVID-19). Nesse mesmo ano, ocorreram cinco atividades de formação, acessadas pelos professores por meio de plataforma digital criada para esse propósito. Essa oportunidade de continuar em contato com os professores possibilitou um trabalho mais organizado e interconectado.

A partir de sugestões dos próprios professores que se reuniram em 2019, os encontros seguintes buscaram um trabalho sequencial, com foco nas necessidades apontadas: criação de planos trimestrais coletivos; sugestões de atividades relacionadas aos níveis de escrita; alfabetização e letramento; inovação da prática; uso de literatura para ajudar na leitura e na escrita; esclarecimentos maiores sobre a BNCC; neurociências/método fonético/boquinhas; estudo de metodologias.

Como não cabe aqui um detalhamento do trabalho com todas as demandas apontadas, destaca-se que há atividades dentro da perspectiva do letramento, pois acredita-se que um trabalho com vistas a compreender as práticas sociais de alunos e professores poderá ajudar os docentes a saberem como tratar cada um dos aspectos destacados por eles.

Acredita-se na troca de experiências e discussão coletiva. É importante que haja a presença de especialistas de diferentes áreas, de acordo com as necessidades apontadas, mas deve sempre haver momentos de preparação e planejamento sobre como aplicar o que foi visto com os alunos, trazendo os elementos aprendidos para a rotina da sala de aula.

No próximo item, serão conhecidos, de forma um pouco mais aprofundada, os três estudos selecionados para dialogarem com a pesquisa descrita nesta seção. 


\section{PROJETOS DE FORMAÇÃO CONTINUADA: IDEIAS NORTEADORAS PARA NOVAS PROPOSTAS}

Nesta seção, serão detalhados três estudos que abordam projetos de formação de professores, relacionados ao processo de alfabetização e letramento. São ações realizadas com docentes de diferentes redes públicas do país, em diferentes momentos. Os estudos foram selecionados por terem sido realizados em diferentes regiões do país e por terem como tema a alfabetização e o letramento. Além disso, dialogam com a presente pesquisa de Doutorado.

O primeiro estudo, de Eitelven e Fronza (2012), relata momentos de um trabalho realizado com dois grupos de professores de séries iniciais participantes do programa de formação continuada Pró-Letramento, Alfabetização e Linguagem, oferecido pelo MEC, com coordenação da Universidade Federal de Pernambuco (UFPE), em parceria com um município da serra gaúcha, conforme supramencionado.

Os encontros de formação envolveram tarefas de elaboração de perguntas sobre temas como letramento, alfabetização, gênero discursivo, leitura, oralidade, produção de texto e avaliação. Ocorreu uma conscientização de que o Programa ia ao encontro das necessidades dos professores, pois a formação continuada busca aliar teoria e prática.

Houve, também, momentos de discussão teórica e de reflexões sobre o papel e a identidade do professor e do aluno. Como as autoras do texto relatam, essa foi uma atividade simples, mas rica, pois tratou da importância do professor como ser humano, que está em interação com seus alunos e disponibiliza a eles contatos com linguagens.

Em sua primeira etapa, o programa Pró-Letramento tratou, principalmente, sobre os processos de alfabetização e letramento. Os professores puderam ler, debater e socializar ideias para conhecer e compreender os 
processos em foco. Dentro dessa temática, houve momentos chamados de Leitura Deleite, uma estratégia de aquisição de conhecimento, aprendizagem e motivação, com foco no prazer de ler. A Leitura Deleite passou a ser conteúdo diário em sala de aula, engajando também outros professores não participantes do Pró-Letramento. Passou a circular quinzenalmente entre os professores a chamada Sacola Deleite, bolsa artesanal, com imagens infantis e sugestões de leitura das professoras em formação. Essa sacola inspirou uma reflexão sobre as leituras particulares dos professores, os quais devem servir de modelo para os seus alunos.

Esses foram os aspectos que se destacaram no programa de formação continuada realizado no município da serra gaúcha, sob a visão de Eitelven e Fronza (2012). O programa possibilitou às docentes refletir a respeito da importância de uma aprendizagem significativa para o desenvolvimento do processo de ensino e aprendizagem. Isso se deu pelo estímulo à leitura de diferentes gêneros textuais, promovendo um acesso dos alunos a eventos de letramento. Destaca-se a presença do professor mediando o processo, interagindo, comentando, questionando e mobilizando o conhecimento de mundo dos alunos.

Foram oportunidades que contribuíram para o crescimento profissional e pessoal das participantes, que se tornaram mais críticas em relação ao processo de ensino-aprendizagem e apresentaram maior compreensão sobre o embasamento teórico. Espera-se, a partir da formação, que as professoras não mais retornarão à escola aplicando metodologias descontextualizadas e sem práticas de letramento (EITELVEN; FRONZA, 2012).

O outro estudo que serviu como inspiração para este artigo foi a pesquisa de Mestrado de Sousa (2016), realizada na Universidade Federal de Minas Gerais 
(UFMG), motivada por um projeto desenvolvido no município de Lagoa Santa/MG, o Alfaletrar ${ }^{10}$, que existe desde 2007.

O Projeto Alfaletrar é inovador, pois fundamenta-se na inserção da Educação Infantil nas discussões sobre alfabetização e letramento, integrando e acompanhando os trabalhos de leitura e escrita do Maternal, na Educação Infantil, ao $5^{\mathrm{o}}$ ano do Ensino Fundamental. O projeto, desenvolvido pelo Núcleo de Alfabetização e Letramento, é coordenado pela professora Magda Soares e possui participação de representante da Secretaria Municipal de Educação do município e de uma professora de cada escola.

Semanalmente, as integrantes do núcleo planejam e discutem práticas e estudos sobre assuntos relacionados à alfabetização e ao letramento. As discussões chegam às escolas por meio da professora representante, que acompanha, orienta e ouve as professoras em suas dúvidas, demandas e sugestões. Essa professora realiza nas escolas, mensalmente, reuniões, que são chamadas de "Repasses", para transmitir as discussões do núcleo.

A pesquisa da dissertação de Sousa (2016) foi desenvolvida em uma sala de Educação Infantil II, com crianças de cinco anos. Os instrumentos de coleta de dados foram documentos oficiais do município, entrevistas, registros escritos e fotográficos de atividades e situações nas salas de atividades da turma pesquisada. Buscou-se a identificação de concepções de alfabetização e letramento e suas relações com aquelas do Projeto Alfaletrar. Procurou-se identificar se havia ou não a adoção das proposições do Núcleo de Alfabetização e Letramento.

10 O programa Alfaletrar envolve todas as escolas da rede, e tem como objetivo oferecer a todas as crianças as condições necessárias para prosseguirem com sucesso em sua escolarização e, sobretudo, para se apropriarem de competências indispensáveis à plena inserção na vida social e profissional, como competências de leitura e de produção textual (Fonte: <http://www.alfaletrar.org.br/sobre-o-alfaletrar>). 
A pesquisa utilizou referenciais teóricos com base sócio-histórico-cultural para fornecer meios para compreender o trabalho docente. Um aspecto desse trabalho está relacionado à apropriação da linguagem escrita por crianças de cinco anos. Foram utilizados, dentre outros, estudos de Vigotski (2002) sobre a teoria social do desenvolvimento, considerando o sujeito construído nas relações sociais pela linguagem. A pesquisa também considerou a perspectiva de Bakhtin (2003) sobre o papel do pesquisador de construir conhecimento para desvelar a realidade por meio de textos que surgem das interlocuções da situação de pesquisa.

A análise do material coletado foi feita com base nos seguintes aspectos: as concepções de alfabetização e letramento expressas pelas entrevistadas, a relação entre as concepções de alfabetização e letramento e as práticas docentes, a relação entre essas concepções e aquelas contidas no Projeto Alfaletrar e, finalmente, a interpretação das concepções expressas e das práticas observadas à luz da revisão teórica e a partir do quadro teórico proposto pela teoria sociocultural e sócio-histórica. (SOUSA, 2016, p. 49)

Sousa (2016) informa que o projeto contou com a participação da professora Doutora Magda Soares, a qual considerou que, para que o projeto tivesse avanços significativos, deveria abranger toda a rede de educação municipal. No entanto, como afirma Sousa (2016), houve resistências iniciais de professores que não queriam modificar as suas práticas e não acreditavam no projeto. Outras pessoas eram contra o projeto por questões políticas.

Ainda em relação ao trabalho de Sousa (2016), com a turma Infantil II, ressalta-se que o projeto foi legitimado pela professora da turma. Ficou evidente que foram trabalhados os componentes propostos pelo Projeto Alfaletrar. No entanto, a docente demonstrou preocupação com a organização do tempo e com o planejamento das atividades, com dificuldades para manter a integração do planejamento na perspectiva da criança. 
É inegável a relevância deste projeto, o que se comprova pelo seu tempo de existência como política municipal, pelo alcance de suas ações que atingem todas as professoras do município, pela capacidade de sistematização dos conhecimentos, pelas condições que oferece para a participação das professoras, por sua capilaridade. (SOUSA, 2016, p. 135)

O projeto produz impacto na formação e também na construção da identidade profissional das professoras. Assim, é considerada uma política de êxito, que deve ser seguida pelas escolas do Brasil (SOUSA, 2016).

O terceiro estudo apresentado neste artigo é o da tese de Doutorado de Nunes (2018), efetivado na Universidade de Lisboa, mas realizado no Brasil, pela pesquisadora brasileira.

A investigação diz respeito à formação continuada de professores, centrada na escola, nas áreas de alfabetização e letramento, por meio de uma pesquisa-ação. Destaca-se que a pesquisadora trabalhou como coordenadora de um Curso de Especialização em Letramento e Formação de Professores, oferecido pela Universidade do Estado do Pará (UEPA), onde ouvia queixas frequentes sobre as limitações nas práticas pedagógicas em relação a alfabetizar e letrar com qualidade.

A pesquisa partiu da seguinte questão: “Em que dimensão o processo de formação contínua de professores centrada na escola e a pesquisa-ação desenvolvidas por professoras alfabetizadoras constituíram-se como referências teórico-metodológicas para a melhoria de suas práticas?" (NUNES, 2018, p. 14). Essa pergunta levou a um trabalho com vistas a desenvolver e analisar a prática de formação continuada de professores alfabetizadores, a fim de instituir uma cultura mais autônoma aos docentes, provocando-os para a reflexão e melhoria de suas práticas. Isso tudo por meio de pesquisa-ação, analisando os limites e potencialidades vivenciados no decorrer da pesquisa.

A pesquisa de Nunes (2018) apresentou abordagem sociocrítica, com predomínio de caráter qualitativo. Os dados empíricos produzidos foram do 
período de março a dezembro de 2013, quando houve 29 encontros em escola pública de anos iniciais situada na região metropolitana de Belém/PA. A escola é localizada em um dos bairros mais populosos de Belém, concentrando boa parte da população de baixa renda do local.

É importante frisar que os alunos da escola, que permanecem até o término dos anos iniciais do Ensino Fundamental ( $5^{\circ}$ ano), deveriam sair alfabetizados, mas muitos deles apresentam lacunas significativas de alfabetização e letramento, conforme indica Nunes (2018), sendo categorizados como analfabetos funcionais.

Participaram do estudo quatro professoras com Licenciatura em Pedagogia, duas professoras de $1^{o}$ ano, uma professora de $2^{o}$ ano e uma professora de $3^{\circ}$ ano. Essas profissionais tinham 11, 17, 16 e 25 anos de docência, respectivamente. Após o convite feito pela pesquisadora, todas se sentiram motivadas a participar do estudo para poderem melhorar suas práticas pedagógicas, encontrar diferentes estratégias e adquirir um novo olhar a respeito das aprendizagens nas áreas de alfabetização e letramento.

Foram realizadas entrevistas, de forma coletiva, no início e no final da investigação-formação, para haver um diagnóstico que servisse de referência para fundamentar a formação. Além disso, elaboraram-se três metas para o trabalho: "que a formação partisse das necessidades formativas; fosse centrada em uma perspectiva reflexiva das práticas e, também, que contemplasse a formação para a pesquisa" (NUNES, 2018, p. 118). Além disso, houve sessões de observação participante, pela pesquisadora, para verificar a apropriação pelas professoras do conteúdo teórico e metodológico trabalhado na formação.

Ao pensar nos resultados, é importante considerar o lócus adverso dessa investigação. Além disso, as professoras que participaram da pesquisa não são desprovidas de reflexividade sobre o seu trabalho e sobre o contexto onde atuam. No entanto, destaca-se o desânimo que as estava impedindo de tentarem mudar 
as suas práticas, pelo fato de elas alegarem que mudar as práticas não depende apenas dos professores (NUNES, 2018).

Ao final do estudo, Nunes (2018) salienta que a reflexão sobre o seu trabalho ajudou as docentes a analisarem caminhos, elaborarem melhores processos de ensino-aprendizagem e, consequentemente, a melhorarem profissionalmente. Além disso, as professoras alegaram que a pesquisa-ação as ajudou a se tornarem mais atentas e responsáveis durante suas práticas. Elas apontaram que gostariam de continuar pesquisando sobre suas práticas escolares, que esse é o caminho para a formação contínua.

A pesquisadora mostrou-se satisfeita ao final do estudo, ao perceber que seu objetivo foi alcançado, pelo fato de que

as docentes tiveram grande protagonismo, pois puderam desenvolver a autonomia didática; partilhar saberes e experiências; aprender e se envolver em situações enriquecedoras; refletir colegiadamente acerca dos problemas científicos e pedagógicos enfrentados por elas, bem como definir colaborativamente formas de minimizar as lacunas diagnosticadas. (NUNES, 2018, p. 268)

Com base nos apontamentos desta seção, na continuidade deste artigo, faz-se breve reflexão sobre os três estudos, considerando as práticas utilizadas para os trabalhos de formação continuada realizados. A discussão busca contribuir para outros estudos que investigam propostas de trabalhos de formação continuada em diferentes contextos.

\section{PERCEPÇÕES E REFLEXÕES ACERCA DE ASPECTOS CONSIDERADOS RELEVANTES NOS ESTUDOS}

Inicialmente, é importante enfatizar que, para que seja realizado um trabalho de formação de professores de excelência, os docentes envolvidos devem mostrar interesse no seu próprio aperfeiçoamento. Não há como realizar 
uma atividade que renda bons resultados com pessoas desmotivadas ou que não acreditam no trabalho a ser desenvolvido.

Ao observar os três estudos selecionados para este artigo (EITELVEN; FRONZA, 2012; SOUSA, 2016; NUNES, 2018), percebe-se que o terceiro foi o único realizado com educadores que escolheram ficar no projeto até o final, já que foi um trabalho realizado com professoras que estavam de fato determinadas a melhorar suas práticas pedagógicas. Isso não significa que os outros professores não estivessem interessados, mas, nesse caso, o fato está bem claro no texto. No entanto, a escola participante da pesquisa foi selecionada pela pesquisadora (cf. NUNES, 2018), e o trabalho se limita a um grupo menor de pessoas. Nesse caso, menos docentes têm a oportunidade de participar das atividades.

O projeto desenvolvido exclusivamente para a dissertação de Sousa (2016), com uma turma de Educação Infantil II (com número de participantes delimitado pela pesquisa), serviu como uma forma de checagem da abrangência e da eficácia do projeto Alfaletrar.

Os estudos de Eitelven e Fronza (2012) e o projeto Alfaletrar, analisado por Sousa (2016), são práticas de formação vinculadas a projetos maiores, propostos pelos governos (federal e municipal). Isso faz com que eles atinjam um número maior de professores. No entanto, eles têm a desvantagem de ter participação compulsória. Há aspectos positivos e negativos nesse tipo de projeto. Ao mesmo tempo que mais professores têm a oportunidade de participar das formações, nem todos participam porque realmente querem, podendo desmotivar alguns colegas. Por isso, o mais importante é que a formação seja muito bem planejada, buscando atingir ao máximo as necessidades locais, satisfazendo mais professores.

De acordo com Gatti (2016), deve haver a perspectiva de uma visão integradora, com combinações importantes de atividades educacionais direcionadas não só a atividades importantes de um contexto, mas 
desenvolvendo atitudes e comportamentos de convivência, partilha, tolerância, observando-se limites de consensos e dissensos, também voltados ao desenvolvimento pessoal dos alunos.

Também é importante observar como algumas práticas de formação rendem frutos que vão além da sala de aula. Um exemplo que pode ser seguido por professores e alunos em geral é o da Leitura Deleite (EITELVEN; FRONZA, 2012). A Sacola Deleite ${ }^{11}$, que pode circular dentro e fora da escola, é um recurso para que os alunos tenham contato com a leitura. A sacola pode conter obras de diversos gêneros (poemas, contos, crônicas, imagens, sugestões de referências bibliográficas), que podem ir se estendendo no decorrer do ano. O importante é que os alunos a tenham como estímulo e que seja despertada a sua curiosidade em relação ao conteúdo da sacola.

Como exemplo para os alunos e como estímulo de leitura para os professores, como mencionam Eitelven e Fronza (2012), a Sacola Deleite deveria circular também entre os docentes. Ela pode ser recheada de notícias, artigos, contos, crônicas, poemas, enfim, tudo o que possa agregar algum conhecimento aos professores e despertar neles um interesse ainda maior pela leitura.

No estudo de Sousa (2016), vinculado ao projeto Alfaletrar, observa-se a mobilização de uma quantidade maior de professores. A participação de um membro de cada escola para repassar as informações das práticas realizadas para os demais professores das escolas da rede parece importante para a organização das formações. Além dessa metodologia, o fato de o projeto também envolver a Educação Infantil em sua proposta é relevante. Para reforçar isso, destacamos que, nas entrevistas realizadas com os professores do município onde a pesquisa que motivou este artigo está sendo desenvolvida, houve queixas sobre alunos que chegavam no $1^{\mathrm{o}}$ ano do Ensino Fundamental, com idades entre 6 e 7 anos,

11 Com o avanço do uso das tecnologias, a ideia da Sacola Deleite pode ser adaptada. Por exemplo, ao invés de haver uma sacola circulando, pode haver a circulação de textos digitais em sites ou documentos compartilhados. 
sem habilidades que deveriam ser desenvolvidas na Educação Infantil. Como exemplo, de acordo com esses professores, as crianças não sabiam que a escrita ocorre da esquerda para a direita e tampouco como segurar o lápis de forma adequada.

De acordo com Neves et al. (2015), na Educação Infantil, o discurso do brincar não deve deixar em segundo plano as discussões sobre o interesse que as crianças têm pela língua escrita. Como sujeitos sociais, as crianças, durante o processo de desenvolvimento individual, apropriam-se dos sistemas simbólicos de sua cultura. A cultura escrita, nas sociedades letradas, é mediadora das relações sociais. Dessa forma, a inclusão das crianças nessa sociedade remete ao letramento e suas implicações. As autoras defendem que essa discussão deve estar presente no campo da Educação Infantil, uma vez que o processo de escolarização (mesmo com as diferenças em cada etapa) de um número crescente de crianças, de qualquer classe social, inicia aos quatro anos.

A Educação Infantil deve ser tema de estudos e formações que envolvam letramento. As pessoas, desde muito cedo, são cercadas e bombardeadas de letramento, ou seja, de práticas sociais que envolvem a língua escrita. De acordo com Kleiman (2005), os usos da língua escrita não estão apenas na escola. A escrita está em todos os lados, é parte da paisagem cotidiana, como em anúncios, pontos de ônibus, comércio, serviço público, igrejas, parquinhos, escritórios etc.

Por isso, os professores, desde a Educação Infantil, precisam estar cientes de que as crianças já têm contato com o letramento desde cedo e que as práticas sociais são essenciais para que uma criança consiga compreender a realidade que a cerca. Por esse e todos os demais motivos citados neste artigo, os professores devem valer-se das práticas sociais no planejamento de suas aulas.

Essa tarefa não é fácil. Em dois dos trabalhos analisados (SOUSA, 2016; NUNES, 2018), observa-se uma queixa bastante comum entre os professores em relação à falta de tempo. A professora pesquisada no estudo de Sousa (2016) alega 
que muitas vezes não tem tempo para se dedicar às metas do projeto. No estudo de Nunes (2018), a falta de tempo também é uma reclamação. Essa informação não é novidade para os professores brasileiros que, em grande parte, precisam trabalhar muitas horas, acarretando sobrecarga de trabalho, para conseguirem se manter de forma digna, considerando suas necessidades financeiras inclusive. Com isso, ao pensarmos em práticas de formação, é importante levarmos em conta o fato de que muitos professores não terão tempo para fazer atividades fora de seu horário de trabalho. Por isso, o tempo destinado à formação precisa ser aproveitado da melhor forma possível.

Os aspectos destacados nesse item podem ser úteis para a organização de outros momentos de formação de professores. Percebe-se a necessidade de se levar em consideração fatores como desejo de aprender, que pode e deve ser despertado, práticas de compartilhamento de textos para estímulo à leitura e o letramento da criança antes de ingressar na escola. Não se pode desconsiderar que os professores gostariam de fazer mais para ajudar a melhorar a qualidade da educação, mas a falta de tempo é um empecilho para isso, como alguns docentes têm reportado, conforme dados dos estudos destacados.

\section{CONSIDERAÇÕES FINAIS}

A partir de exemplos concretos, este artigo teve como objetivo pensar a formação continuada de professores alfabetizadores. Muito se fala a respeito do assunto e diversas práticas de formação são realizadas. Contudo, há a necessidade de mais análises a partir de ofertas desenvolvidas, para que boas ideias sejam compartilhadas, discutidas e utilizadas.

Nossa intenção foi provocar uma reflexão sobre aspectos importantes de três trabalhos já existentes. Tal discussão deve contribuir para avanços na pesquisa de Doutorado da qual parte este artigo, mas também pode inspirar 
outras análises semelhantes, compartilhando e discutindo diferentes propostas de formação. Neste caso, a formação foi destinada a professores alfabetizadores, com base no letramento, mas podem ser realizadas pesquisas com foco em outros níveis de ensino e classes de professores.

Todavia, nunca se pode esquecer que cada projeto tem as suas particularidades, dependendo do contexto em que é realizado. No caso dos estudos descritos neste artigo, foi citada a falta de tempo como um fator negativo por parte dos docentes. Acredita-se que esse seja um problema bastante comum na realidade brasileira, principalmente na de professores das redes públicas. Como essa adversidade depende de muitas ações para ser resolvida, precisamos pensar em como proporcionar momentos de formação no horário de trabalho dos professores, por meio de alternativas eficientes. Os projetos mencionados foram realizados dentro da carga horária dos professores. Tal disponibilidade contribui para que os docentes se engajem nos projetos com mais facilidade. Revela-se, com base nesse fator, a urgência de políticas de formação continuada que garantam aos professores qualificação profissional dentro de seu espaço de trabalho, inserida em suas horas letivas.

Como fechamento para este artigo, salientamos a importância da união entre as escolas e as universidades. Há muitas pesquisas desenvolvidas na área da educação, dentre estas estão os exemplos dos estudos mencionados (EITELVEN; FRONZA, 2012; SOUSA, 2016; NUNES, 2018). Mais estudos como esses são essenciais, pois o propósito das pesquisas é que elas atinjam as pessoas. No caso da escola, ela se beneficia com estudos que chegam a ela de forma gratuita, com o objetivo de auxiliar essa instituição que tanto luta para atingir o propósito de educar com qualidade. 


\section{REFERÊNCIAS}

BAKHTIN, Mikhail. Estética da criação verbal. $1^{a}$ ed. São Paulo: Martins Fontes, 2003.

CHIMENTÃO, Lilian Kemer. O significado da formação continuada docente. In: $4^{\circ}$ CONPEF - Congresso Norte Paranaense de Educação Física Escolar. Londrina: CONPEF, julho de 2009. Disponível em: $<$ http://www.uel.br/eventos/conpef/conpef4/trabalhos/comunicacaooralartigo/artigoco moral2.pdf>. Acesso em: 27/11/2020.

CRUZ, Shirleide Pereira da Silva. A construção da profissionalidade polivalente na docência nos anos iniciais do ensino fundamental: sentidos atribuídos às práticas por professoras da Rede Municipal de Ensino do Recife, PE. 2012. 280f. Tese (Doutorado em Educação), Centro de Educação, Universidade Federal de Pernambuco, Recife.

DORNELLES, Leni Vieira. A produção de sujeitos alfabetizados. In: DALLA ZEN, Maria Isabel Habckost; XAVIER, Maria Luisa (orgs.). AlfabeLetrar: Fundamentos e Práticas. Porto Alegre: Mediação, 2019, p. 21-30.

EITELVEN, Adriane Angheben; FRONZA, Cátia de Azevedo. "Batizando e ressignificando práticas pedagógicas" no ensino da língua materna: o papel da formação continuada. Revista Brasileira de Linguística Aplicada. Belo Horizonte, v. 35, n. 1, p. 11-29, 2012.

FERREIRA, Sandra Patrícia Ataíde; DIAS, Maria da Graça Bompastor Borges. A Escola e o Ensino da Leitura. Psicologia em Estudo. Maringá, n. 7, v. 1, p. 39-49, 2002.

FERREIRO, Emilia. Reflexões sobre alfabetização. 24ํㅡㄹ ed. São Paulo: Cortez, 2001.

GATTI, Bernardete. Formação de professores: condições e problemas atuais. Revista Internacional de Formação de Professores. Itapetininga, n. 1, v. 2, p. 161-171, 2016.

HEIGHAM, Juanita; CROKER, Robert. Qualitative Research in Applied Linguistics - a practical introduction. $1^{\mathrm{a}}$ ed. London: Palgrave, 2009.

KATO, Mary Aizawa; MOREIRA, Nadja Ribeiro; TARALLO, Fernando Luiz. Estudos em alfabetização: retrospectivas nas áreas da psico e da sociolinguística. $1^{\underline{a}}$ ed. Campinas: Pontes, 1998.

KERSCH, Dorotea Franck. O letramento acadêmico na formação continuada: constituição de autoria e construção de identidades. Desenredo. Passo Fundo, n. 10, v. 14, p. 54-64, 2014.

KLEIMAN, Ângela. Preciso ensinar Letramento? Não basta ensinar a ler e a escrever? $1^{\underline{a}}$ ed. Campinas: CEFIEL, 2005.

KLEIMAN, Ângela; VIANNA, Carolina Assis Dias; GRANDE, Paula Baracat de. A Linguística Aplicada na contemporaneidade: uma narrativa de continuidades na transformação. Calidoscópio. São Leopoldo, n. 17, v. 4, p. 724-742, 2019.

LUIZ, Simone Weide; HENTZ; Maria Izabel Bortolli; FRONZA, Cátia de Azevedo; PACHECO, Alice Virgínia Oliveira. A BNCC e o ensino de leitura e escrita no primeiro 
ano do Ensino Fundamental: o trabalho do professor. ReVEL, [s. 1.], v. 17, n. 33, p. 68-84, 2019.

MAGALHÃES, Lígia Karam Corrêa de; AZEVEDO, Leny Cristina Soares Souza. Formação Continuada e suas implicações: entre a lei e o trabalho docente. Cadernos CEDES. Campinas, n. 95, v. 35, p. 15-36, 2015.

MATENCIO, Maria de Lourdes Meirelles. Leitura, produção de textos e a escola. $1^{\underline{a}}$ ed. Campinas: Mercado de Letras, 2000.

MOREIRA, Maria Elisa Rodrigues; ROCHA, Elaine Andreia Gonçalves Moreira da. Alfabetizar letrando: novos desafios no ensino da língua escrita. Saberes Interdisciplinares. São João Del Rei, v. 6, n. 12, p. 25-42, 2013.

NEVES, Vanessa Ferraz Almeida; CASTANHEIRA, Maria Lúcia; GOUVEA, Maria Cristina Soares. O letramento e o brincar em processos de socialização na educação infantil brincadeiras diferentes. Revista Brasileira de Educação. Rio de Janeiro, v. 20, n. 60, p. 215-244, 2015.

NUNES, Herika Socorro da Costa. Formação continuada de professores do ensino fundamental centrada na escola: reflexão e pesquisa-ação para a mudança de concepções e práticas de alfabetização e letramento. 2018. 316f. Tese (Doutorado em Educação), Instituto de Educação, Universidade de Lisboa, Lisboa.

OLIVEIRA, Ana Carolina Finati de; OLIVEIRA, Tayná; MAZOTE, Maria Célia Guilhen. A crise da leitura na escola: algumas considerações e implicações. Revista Pedagogia em Foco. Iturama, v. 10, n. 4, p. 114-122, 2015.

ROJO, Roxane; BARBOSA, Jaqueline Peixoto. Hipermodernidade, multiletramentos e gêneros discursivos. 1ª ed. São Paulo: Parábola, 2009.

SOARES, Magda. Alfabetização e Letramento. 5aㅡ ed. São Paulo: Contexto, 2003.

SOARES, Magda. Alfabetização: a questão dos métodos. $1^{\underline{a}}$ ed. $2^{\underline{a}}$ reimpressão. São Paulo: Contexto, 2018.

SOUSA, Elisabeth Vieira Rodrigues de. Alfabetização e letramento na educação infantil: um estudo de caso em uma instituição de educação infantil no município de Lagoa Santa. 2016. 165f. Dissertação (Mestrado em Educação), Departamento de Educação, Universidade Federal de Minas Gerais, Belo Horizonte.

VIGOTSKI, Lev Semyonovich. A formação social da mente. $6^{\underline{a}}$ ed. São Paulo: Martins Fontes, 2002.

Nota do editor:

Artigo submetido para avaliação em: 30 de setembro de 2020.

Aprovado em sistema duplo cego em: 25 de fevereiro de 2021. 